\title{
Effectiveness of the Combined Use of Microelements and Tetravit in Calves of the Dairy Period
}

\author{
Alexey Trebukhov ${ }^{1}$, Elena Shaganova ${ }^{1}$, Yulia Chekunkova $^{2}$, Nadezhda Momot $^{3}$, and Yulia \\ Kolina $^{3}$ \\ ${ }^{1}$ Altai State Agricultural University, 656049, Barnaul, Russian Federation \\ ${ }^{2}$ Federal Altai Scientific Centre of Agro-BioTechnologies, 656910, Barnaul, Russian Federation \\ ${ }^{3}$ Primorsk State Agricultural Academy, 692510, Ussuriysk, Russian Federation
}

\begin{abstract}
Use of biologically active additives in feeding young animals is the most important element of resource-saving technologies. The aim of the study was to study the effectiveness of use of vitamin and mineral nutrition on the growth and development of young animals. 3 groups of calves were formed at the age of 10 days. Animals of the control group received the basic diet $(\mathrm{OR})$, the II-experimental group received $\mathrm{OR}+$ salts of microelements and the calves of the III-experimental group received OR + salts of microelements and tetratwit in doses from 1 to 3 months $1.5 \mathrm{mg}$, from 3 to 5 months $-2.0 \mathrm{mg}$ and from 5 to 6 months $-3.0 \mathrm{mg}$. Tetravit was injected once every 2 weeks throughout the study. It was found that feeding the salts of microelements (copper, zinc, cobalt, manganese, iodine) to calves during the dairy period contributes to their more intensive development and growth of their meat productivity, both in combination with tetravite and without it. Use of salts of microelements separately, and in combination with a multivitamin preparation (tetravit) contributes to a significant increase in the studied hematological parameters in young animals, relative to control analogues.
\end{abstract}

\section{Introduction}

An integral part of the stable and effective development of livestock breeding is provision of full-value diets for farm animals, balanced in all essential nutrients. Departure from these conditions leads not only to a significant decrease in productivity, but also to development of various metabolic diseases (ketosis, osteodystrophy, hepatosis, and etc.) [1,2] and, as a consequence, to a decrease in the productive longevity of livestock and its early culling [3].

Wherein, young animals are more sensitive to imbalance of mineral and vitamin components in the diet than adults $[4,5]$. A growing organism depends on the qualitative composition of the diet, due to the high need for "building" elements to maintain proper growth and development, as a result, even a small excess or lack of necessary vitamins or minerals leads to development of clinically expressed pathologies [6-8].

At present, feed additives and premixes are widely used to optimize diets for deficient elements in formulations that include various biologically active substances (enzymes, vitamins, macro- and microelements, protein components of various nature, and etc.) [9- 
11]. Use of feed additives containing vitamin and mineral components, allows to balance the diet of young animals according to these biologically active elements, ensuring the normal functioning of all metabolic processes in the body $[12,13]$.

The aim of the study was to study the effectiveness of use of vitamin and mineral nutrition on the growth and development of young animals.

\section{Materials and Study Methods}

The studies were carried out at Uchkhoz Prigorodnoye JSC in the city of Barnaul for 6 months in the winter-summer period. The object of the study was black-and-white calves at the age of 10 days, with a live weight of $26.6 \pm 0.5 \mathrm{~kg}$. 3 groups of calves were selected. Young animals for the study were selected according to the principle of analogues, according to the methodology based on the selection of animals by weight: with an intergroup difference of no more than $5 \%$ and an intragroup difference of no more than $10 \%$. The scheme of scientific and economic experience is presented in Table 1.

Table 1. Scheme of scientific and economic experience

\begin{tabular}{|l|c|l|}
\hline \multicolumn{1}{|c|}{ Indicator } & $\begin{array}{c}\text { Number of } \\
\text { heads }\end{array}$ & \multicolumn{1}{c|}{ Feeding ration } \\
\hline I-control & 5 & Basic Diet (OR) \\
\hline $\begin{array}{l}\text { II- } \\
\text { experimental }\end{array}$ & 5 & OR + microelement additives \\
\hline $\begin{array}{l}\text { III- } \\
\text { experimental }\end{array}$ & 5 & $\begin{array}{l}\text { OR + microelement additives + tetravit in doses, ml/head: from 1 to 3 } \\
\text { months }-1.5, \text { from 3 to 5 months }-2.0 \text {, and 5-6 months }-3.0 ; \\
\text { intramuscular injection interval is every 2-3 weeks }\end{array}$ \\
\hline
\end{tabular}

Throughout the study, the calves of the studied groups received the ration used on the farm (basic ration - OR). This diet included: colostrum, milk (whole and skimmed), corn silage, meadow hay, fodder beets, wheat turf.

Depending on the month of the study (age of young animals), the nutritional value of the diet varied in feed units within 2.1-4.5 g, metabolic energy - 9.4-16.4 g, digestible protein - 16.5-30.8 $\mathrm{mJ}$, calcium and phosphorus - 9.4-16.5 $\mathrm{g}$ and 13.6-33.8 g, respectively. The diet was balanced according to the VASKhNIL standards for 17 most important indicators [14].

The juveniles of the second experimental group in the diet included sulfate salts of microelements (manganese, copper, cobalt, zinc), as well as iodide potassium salt.

In the third experimental group of calves, salts of microelements were added to the diet, similar to the animals of the second group, and intramuscular injections of tetravit were carried out once every 2 weeks throughout the study. Salts of microelements were given to young animals with concentrates once a day. This mineral additive was prepared before feeding by means of step mixing.

\section{Study Results}

In the course of our study, it was found that during the entire study period, young animals who received vitamin and mineral additives showed significant changes in live weight, both between the experimental groups and relative to the control group. The results of changes in the live weight of calves are provided in Table. 2. 
Table 2. Live weight of black-and-white heifers in the milk period

\begin{tabular}{|l|c|c|c|}
\hline \multirow{2}{*}{ Study month } & \multicolumn{3}{|c|}{ Group } \\
\cline { 2 - 4 } & I-control & II-experimental & III-experimental \\
\hline At birth & $27.2 \pm 0.2$ & $26.0 \pm 0.8$ & $27.0 \pm 0.6$ \\
\hline 1 month & $40.7 \pm 0.5$ & $40.0 \pm 2.7$ & $40.5 \pm 1.6$ \\
\hline 2 months & $61.2 \pm 1.3$ & $62.8 \pm 1.3$ & $65.2 \pm 1.7$ \\
\hline 3 months & $82.0 \pm 1.6$ & $91.4 \pm 2.3$ & $95.8 \pm 1.6$ \\
\hline 4 months & $97.6 \pm 2.1$ & $106.6 \pm 1.3$ & $115.3 \pm 1.8$ \\
\hline 5 months & $120.0 \pm 1.4$ & $133.0 \pm 2.1$ & $142.0 \pm 2.7$ \\
\hline 6 months & $138.8 \pm 1.7$ & $155.8 \pm 2.1$ & $165.1 \pm 2.8$ \\
\hline
\end{tabular}

Analysis of Table 2 showed that the average live weight of calves of all studied groups significantly increased monthly. Wherein, by the second month of observation, the body weight of young animals of the third experimental group was higher than the control peers by $6.5 \%(\mathrm{P} \leq 0.05)$ and by $3.8 \%$ relative to the analogs of the second group. By the third month of the study, the analyzed indicator of the calves of the second experimental group was significantly higher than the control peers during this period by $11.4 \%(\mathrm{P} \leq 0.05)$, and the young animals of the group receiving the vitamin and mineral supplement exceeded the weight of the control calves by $16.8 \%(\mathrm{P} \leq 0.05)$ and calves of the second experimental group - by $4.8 \%$. Wherein, there were no significant intergroup differences between the experimental groups.

The fourth month of observation was characterized by a significant excess of the live weight of calves in the third experimental group, relative to the control and the second experimental group, by $18.3 \%$ and $8.2 \%$, respectively. The intergroup difference between the second experimental group and the control one was $9.2 \%$ in favor of the experiment calves. A similar trend was observed in subsequent studies. So, five months after birth, the average live weight of young animals, in the diet of which the vitamin-mineral premix was added, was higher than the analyzed control parameter by $22.0 \mathrm{~g}(18.3 \%)$, and a month later (6 study) - by $26.3 \mathrm{~g}(19 \%)$. The average group values of the experiment ones during this period were higher in the third experiment group compared to the second one, by $6.7 \%(\mathrm{P} \leq 0.05)$ by the fifth month, and by $6 \%(\mathrm{P} \leq 0.05)$ by the final study.

In the group of calves that received the basic diet in combination with a mineral additive (experimental group 2), body weight indicators were higher than those of young calves in the diet, which did not have such an additive (control group), in the fifth study - by $11 \%$ $(\mathrm{P} \leq 0.05)$.

Therefore, by the final study, the young animals of the 3rd experimental group exceeded their peers in the second experimental group by $9.3 \mathrm{~kg}(\mathrm{P} \leq 0.05)$, and the control one - by $26.3 \mathrm{~kg}(\mathrm{P} \leq 0.05)$.

The gain in live weight of calves is provided in Table 3.

Table 3. Average daily growth of heifers of black and motley breed in the milk period

\begin{tabular}{|c|c|c|}
\hline \multirow{2}{*}{ Group } & \multicolumn{2}{|c|}{ Live weight gain } \\
\cline { 2 - 3 } & average daily, g & absolute, $\mathrm{kg}$ \\
\hline I-control & $620 \pm 10$ & 111.6 \\
\hline II-experimental & $719 \pm 7$ & 129.8 \\
\hline III-experimental & $767 \pm 13$ & 138.1 \\
\hline
\end{tabular}

The average daily gain in live weight of calves of the second experimental group, which received only a mineral additive in addition to the main diet, was higher than the control 
calves by $99 \mathrm{~g}$. Calves of the third experimental group, in accordance with the experimental scheme, in addition to the salts of microelements, who received an injection of Tetravit, showed the greatest daily weight gain, which exceeded the same indicator of the control group by $147 \mathrm{~g}$ and the second experimental group - by $48 \mathrm{~g}$.

Blood plays an important role in the body of animals. It has a relatively constant composition, but to a certain extent it is capable of reflecting the changes occurring in the animal organism under the influence of various factors $[15,16]$. For the purpose of multifactorial study of the effect on the growth and development of microelements and vitamins in young animals, a study of their blood was carried out.

Laboratory blood tests are provided in Table 4.

Table 4. Hematological blood tests in calves $(M \pm n ; n=15)$

\begin{tabular}{|c|c|c|c|}
\hline \multirow{2}{*}{ Age, months } & \multicolumn{3}{|c|}{ Group } \\
\hline & I-control & II-experimental & III-experimental \\
\hline \multicolumn{4}{|c|}{ Erythrocytes, $10^{12} / 1$} \\
\hline in 15 days & \multicolumn{3}{|c|}{$5.27 \pm 0.21$} \\
\hline 2 & $7.42 \pm 0.39$ & $8.32 \pm 0.42$ & $8.30 \pm 0.30$ \\
\hline 3 & $7.38 \pm 0.2$ & $7.52 \pm 0.3$ & $7.71 \pm 0.4$ \\
\hline 4 & $7.36 \pm 0.25$ & $7.26 \pm 0.17$ & $7.46 \pm 0.12$ \\
\hline 5 & $6.86 \pm 0.36$ & $7.64 \pm 0.22$ & $7.21 \pm 0.21$ \\
\hline 6 & $6.84 \pm 0.09$ & $7.24 \pm 0.22$ & $7.28 \pm 0.08$ \\
\hline \multicolumn{4}{|c|}{ Leukocytes, $10^{9} / 1$} \\
\hline in 15 days & \multicolumn{3}{|c|}{$7.28 \pm 0.40$} \\
\hline 2 & $6.8 \pm 0.74$ & $7.20 \pm 0.43$ & $7.64 \pm 0.58$ \\
\hline 3 & $6.4 \pm 0.4$ & $8.1 \pm 0.4$ & $7.68 \pm 0.5$ \\
\hline 4 & $5.26 \pm 0.27$ & $9.52 \pm 0.30$ & $7.80 \pm 0.60$ \\
\hline 5 & $9.44 \pm 0.65$ & $9.24 \pm 0.26$ & $7.32 \pm 0.58$ \\
\hline 6 & $6.7 \pm 0.3$ & $7.36 \pm 0.63$ & $7.74 \pm 0.32$ \\
\hline \multicolumn{4}{|c|}{ Hemoglobin, $\mathrm{g} / \mathrm{l}$} \\
\hline in 15 days & \multicolumn{3}{|c|}{$75.1 \pm 4.2$} \\
\hline 2 & $99.4 \pm 5.5$ & $99.6 \pm 5.5$ & $106.0 \pm 4.1$ \\
\hline 3 & $101.8 \pm 4.2$ & $105.4 \pm 2.6$ & $106.0 \pm 4.1$ \\
\hline 4 & $105.4 \pm 1.7$ & $115.6 \pm 1.6$ & $103.4 \pm 5.6$ \\
\hline 5 & $101.0 \pm 2.2$ & $101.8 \pm 2.1$ & $104.2 \pm 1.5$ \\
\hline 6 & $95.2 \pm 3.9$ & $98.2 \pm 1.9$ & $103.4 \pm 1.0$ \\
\hline \multicolumn{4}{|c|}{ Carotene, $\mu \mathrm{mol} / 1$} \\
\hline 2 & $7.5 \pm 0.4$ & $10.6 \pm 4.1$ & $11.3 \pm 0.8$ \\
\hline 3 & $8.3 \pm 0.2$ & $10.3 \pm 5.6$ & $10.7 \pm 0.6$ \\
\hline 4 & $10.7 \pm 0.1$ & $10.1 \pm 0.4$ & $10.3 \pm 0.1$ \\
\hline 5 & $8.0 \pm 0.9$ & $8.8 \pm 0.6$ & $10.4 \pm 0.5$ \\
\hline 6 & $11.1 \pm 0.2$ & $8.6 \pm 0.3$ & $10.2 \pm 0.3$ \\
\hline
\end{tabular}

Table 3 shows that the number of erythrocytes was significantly lower in the blood of calves from the control group during the entire experiment. So, in the second study, the level of erythrocytes was higher in the first and second experimental groups compared to the control one in the second study by $12.13 \%$ and $11.9 \%$, in the fifth - by $11.4 \%$ and $5 \%$, and in the sixth - by $5.8 \%$ and $6.4 \%$, respectively. Wherein, there were no significant intergroup differences in the experimental groups, with the exception of the fifth study, in which the highest concentration of the analyzed indicator was in the first experimental group (by $6 \%$ ) relative to the second.

The number of leukocytes in the blood of calves from the experimental groups by the third study was higher than the control peers. By the final study, the content of leukocytes in the blood of young animals of the first experimental group was $9.8 \%$ more leukocytes in 
the blood of the control, and in the second experimental group - by $15.5 \%$. There were no significant differences between the experimental groups, except for the fourth and fifth studies, during which the analyzed parameter was higher in the blood of calves from the first experimental group by $22 \%$ and $26 \%$, respectively, compared to the second experimental group. Wherein, despite the higher values of this indicator during the entire experiment in the blood of calves of the first experimental group, relative to the second one, by the final study the number of leukocytes was less by $5 \%$.

The concentration of hemoglobin in the study groups did not have significant differences until the fourth month of observation, during which the content of this indicator was maximum in the first experimental group $(115.6 \pm 1.6 \mathrm{~g} / \mathrm{l})$ exceeding the control values by $9.7 \% \quad(p \leq 0.05)$ and the second experimental group - by $11.8 \% \quad(p \leq 0.05)$. Subsequently, the hemoglobin level in the first experimental group decreased almost to the level of the second study, but was still $3.2 \%$ higher than the control peers. The hemoglobin content in the second experimental group, by the second month of the study, as in all the observed groups, increased by 1.4 times relative to the first study $(p \leq 0.05)$, despite a slight decrease. By the final observation, the level of the described indicator was significantly higher than the control calves by $8.6 \%$, and the peers of the first experimental group — by $5.3 \%$.

It shall be noted that in the second study, the hemoglobin concentration increased in all groups relative to the baseline data, but there were no significant differences between the groups during this period.

The change in the blood carotene level of calves from the experimental groups as a whole had a similar dynamics with a decrease towards the end of the study. So, by the age of six months, the concentration of carotene was significantly higher in the blood of young animals of the second experimental group by $18.6 \%$ relative to the first control one. It shall be noted that, despite significant fluctuations in the analyzed indicator in the control blood, $7.5 \pm 0.4-11.1 \pm 0.2 \mu \mathrm{mol} / 1$, by the end of the study in this group, the carotene content in the blood was the highest among the peers of the studied groups, which allows to conclude that use of these drugs does not affect their concentration in the blood, providing, at the same time, a more stable level in the blood.

\section{Conclusions}

1. Feeding the salts of microelements (copper, zinc, cobalt, manganese, iodine) to calves during the milk period contributes to their more intensive development and growth of their meat productivity, both in combination with tetravit and without it.

2. Use of salts of microelements separately, and in combination with a multivitamin preparation (tetravit) contributes to a significant increase in the studied hematological parameters in young animals, relative to control analogues.

\section{References}

1. A. V. Trebukhov, Veterinary Medicine, 5, 50 (2021)

2. A. V. Trebukhov, A. A. Elenshleger, IOP Conference Series: Earth and Environmental Science. The proceedings of the conference AgroCON-2019, 012152 (2019)

3. L. Redkozubova, Compound feed, 6, 80 (2018)

4. E. I. Mashkina, Bulletin of the Altay State Agrarian University, 1(159), 113 (2018)

5. O. B. Filippova, Chief zootechnician, 8, 11 (2015) 
6. A. Trebukhov, N. Momot, Yu. Kolina, A. Trebukhov, Igor Kamliya, E3S Web of Conferences, 254, 09007 (2021)

7. A. V. Trebukhov, Bulletin of the Altai State Agrarian University, 6(200), 44 (2021)

8. E. I. Mashkina, Innovations and food security, 3(17), 85 (2017)

9. V. Fisinin, Animal Husbandry of Russia, 9, 62 (2009)

10. L. Yu. Topuria, Bulletin of the Orenburg State Agrarian University, 4(16-1), 82 (2007)

11. S. V. Moshkina, Chief zootechnician, 9, 27 (2012)

12. A. V. Trebukhov, A. A. Elenshlager, S. P. Kovalev, V. N. Denisenko, G. G. Shcherbakov, A. V. Yashin, Ketosis of cows and calves, St. Petersburg, 132 (2019)

13. Yu. Luschai, O. Dutova, E. Shaganova, I. Pleshakova, E. Mashkina, International Research Conference on Challenges and Advances in Farming, Food Manufacturing, Agricultural Research and Education, 342 (2020)

14. A. P. Kalashnikov, Norms and rations for feeding farm animals: a reference guide, M.: Kolos, 456 (2003)

15. G. S. Azaubaeva, Blood picture in animals and birds. Kurgan, Trans-Urals, 168 (2004)

16. I. P. Kondrakhin, Methods of veterinary clinical laboratory diagnostics. M.: Kolos, 520 (2004) 